Twenty two percent of these children with $\mathrm{CDH}$ were still not walking at the age of 18 months. Thus the commonly taught axiom that $\mathrm{CDH}$ does not delay the onset of walking is incorrect. Indeed, in a later study that I made in 1962, into the way in which the diagnosis came to be made in 244 cases of CDH (average age 19 months), 'late walking' was the fourth most common form of presentation (11\%), after 'abnormal gait' (53\%), 'short leg' (29\%), and 'associated deformity' $(21 \%) .{ }^{4}$ No correction was made for gestational age but then $\mathrm{CDH}$ is uncommon among preterm infants. ${ }^{45}$ In conclusion, while the late diagnosis of $\mathrm{CDH}$ is becoming less common, the failure of a term infant to walk at 18 months remains a useful marker for this condition.

PETER M DUNN Department of Child Health, Southmead Hospital, Bristol BS10 5NB

1 Johnson A, Goddard O, Ashurst H. Is late walk ing a marker of morbidity? Arch Dis Child 1990;65:486-8.

2 Davis R, Butler N, Goldstein H. From birth to seven. The 2nd report of the National Child Development Study (1958 cohort). London: Longman, 1972:74-5.

3 Neligan G, Pridham D. Norms for standard development milestones by sex, social class, and place in family. Dev Med Child Neurol and place in famil

4 Dunn PM. The influence of the intrauterine environment in the causation of congenital postural deformities, with special reference to congenital dislocation of the hip. Vols I, II, and III. Cambridge: Cambridge University, 1969. (MD thesis.)

5 Dunn PM, Evans RE, Thearle MJ, Griffiths HED, Witherow PJ. Congenital dislocation of the hip: early and late diagnosis and management compared. Arch Dis Child 1985;60: 407-14.

Drs Fohnson, Goddard, and Ashurst comment: While acknowledging Dr Dunn's point that some degree of delay in achieving motor milestones is to be expected among very preterm infants, the high rate of impairment among the late walkers in this group means that 'immaturity' should not be too readily accepted as the sole reason for late walking. As so often in clinical practice, a balance needs to be achieved between causing unnecessary anxiety to parents and yet remaining aware of the risk of associated impairment in all late walkers, particularly those who were born very preterm

There was just one infant among the late walkers who had associated congenital dislocation of the hip. This had been detected, however, before the age of 18 months.

\section{Lichen sclerosis}

SIR,-As a paediatrician who has encountered eight new cases of lichen sclerosis in young children over a period of 18 months, I would like to add my observations to those of Drs Priestley and Bleehan and Dr Harrington. ${ }^{12}$

The earliest of these cases was a girl aged 6 years, who presented with dysuria and bleeding after a visit to a male neighbour-a regular babysitter. The girl gave a clear account of repeated sexual abuse involving frictional interlabial trauma. The neighbour admitted to these offences as well as to those on other children has since served a prison sentence. The findings were of gross lichen sclerosis with pallor, friability, and haemorrhage, with the hymen showing partial disruption at one site.
Of the other seven cases seen, a further two were associated with clear histories of sexual abuse. In another child, extensive hymenal damage was associated with behavioural and family factors, and abuse remains a worrying possibility.

Lichen sclerosis has therefore been noted by me in three children where sexual abuse was described, as well as in children presented by protective agencies, because of this and other behavioural symptomatology.

The suggestion that the presence of lichen sclerosis in someway excludes sexual abuse must be unacceptable. Indeed, if I were to use the statistical reasoning of Dr Berth Jones et al in terms of my own limited experience, ${ }^{3}$ the presence of these changes would be linked to a sexual abuse diathesis in such significant numbers $(50 \%)$, as to turn this argument on its head with equal frailness.

If lichen sclerosis is the outcome of chronic trauma in some children, then it must follow that every case requires careful study. Perhaps we should also be considering the possibility that these changes may relate to a local immune response to the recurrent presence of substances like semen, or contraceptive lubricant, both in adults and children.

My personal approach is to accept lichen sclerosis in children as a spontaneous unexplained phenomenon. I would not accept hymenal disruption, sexualised behaviour, or a child's disclosure as part of this phenomenon. The presence of lichen sclerosis in these circumstances can neither be considered 'spontaneous' nor 'unexplained'

C SAN LAZARO The Children's Department, The Royal Victoria Infirmary, Queen Victoria Road, Newcastle upon Tyne NEI 4LP

1 Priestley BL, Bleehan SS. Lichen sclerosis and sexual abuse. Arch Dis Child 1990;65:335.

2 Harrington CI. Lichen sclerosis. Arch Dis Child 1990;65:335.

3 Berth-Jones J, Graham Brown RAC, Burns DA. Lichen sclerosis. Arch Dis Child 1989;64: 1204-6.

Surveillance for anaemia: risk factors in pattern of milk intake

SIR,-We were interested to read Mills' study from east London, of the prevalence of anaemia in early infancy, ${ }^{1}$ and fully agree with his conclusion that iron status is closely related to the type of milk consumed.

Prompted by a high reported incidence of iron deficiency in China, and concern in Hong Kong that babies were having a poor iron intake during weaning, in the mid 1980 s we investigated the iron status of a sample of full term healthy Hong Kong Chinese babies. These babies were being followed up to monitor their growth and nutritional state and most were formula fed. Of our initial cohort of 174 babies only 8,4 , and $2 \%$ were breast fed at 2 , 4 , and 6 months respectively. ${ }^{2}$

Mean (SD) daily iron intakes at 6, 12 and 18 months were $8(5), 9(3)$, and $8(3) \mathrm{mg}$ respectively, comfortably within the WHO dietary allowance of 5-10 mg. The mean (SD) haemoglobin concentration in 123 babies, at 18 months was $124(8 \cdot 9) \mathrm{g} / \mathrm{l}$. Eleven had a haemoglobin concentration $<110 \mathrm{~g} / \mathrm{l}$. Of these, seven had $\beta$ thalassaemia trait, two showed a satisfactory response to iron treatment ( $2 \mathrm{mg} / \mathrm{kg} /$ day) for three months, one had an unchanged haemoglobin, and one defaulted further follow up. Three of 112 babies with haemoglobin of $>110 \mathrm{~g} / \mathrm{l}$ had a mean corpuscular volume $<70 \mathrm{fl}$. Mean (SD) serum ferritin concentration at 18 months in 128 infants was $155 \cdot 9(24 \cdot 8) \mu \mathrm{g} / 1$, with only one having a concentration $<7 \mu \mathrm{g} / \mathrm{l}$.

We attributed this very low $(\sim 2 \%$ excluding $\beta$ thalassaemia trait) incidence of iron deficiency to infant feeding practices, which provide: (i) an adequate iron intake during the weaning period from fortified milk formulas, iron fortified cereals, meat, and fish and (ii) a negligible consumption of pasteurised cows' milk with its low iron content and risks of causing occult intestinal blood loss.

These practices contrast with those described in Mills' study, ${ }^{1}$ where, with an incidence of anaemia of $22 \%$, continued breast feeding, with the early giving of pasteurised milk, were risk factors for anaemia. But the value of prolonged formula feeding, with iron fortified milks that comply with international standards, as one means of lessening the incidence of iron deficiency in early childhood, was evident from both our investigations.

D P DAVIES Department of Child Health, University of Wales College of Medicine, Heath Park,

Cardiff CF4 $4 X N$

S S F LEUNG Department of Paediatrics, Prince of Wales Hospital,

Shatin,

Hong Kong

1 Mills AF. Surveillance for anaemia: risk factors in patterns of milk intake. Arch Dis Child 1990; 65:428-31.

2 Leung SSF, Lui S, Lo L, Davies DP. A better guideline on milk requirements for babies below 6 months. Aust Paediatr $\mathcal{f}$ 1988;24: 186-90.

3 Leung SSF, Davies DP, Lui S, Lo L, Yuen P Swaminathan $R$. Iron deficiency in normal healthy Hong Kong infants at 18 months. f Trop Pediatr 1988;34:100-3.

Collecting 24 hour urine samples from children

SIR,-Collection of urine over several hours for metabolic investigations in infants and toddlers is notoriously awkward: disposable napkins frequently produce contaminated samples, and modified cots are only practicable for small infants. ${ }^{12}$ The following modified technique imposes few restraints on the patient, and is therefore metabolically accurate, and may be used for accurate collections of up to 72 hours. $^{3}$

A bag is constructed with a narrow tube inlet and a larger outlet. The Hollister 24 hour paediatric urine collection bag is particularly appropriate, having a reinforced outle provided. The inside pocket of the bag is removed and the bag resealed using a heated bar sealer. A nasogastric tube of approximately $8 F$ guage is inserted $2 \mathrm{~cm}$ through a small hole in the top corner of the bag, and sealed in place using spray on plastic adhesive (for example, Dow Corning) and plastic adhesive tape.

The air diaphragm pump (for example, the Charles Austen series), collection vessels, and tubing are attached to provide an air flow of some 31 per minute, with positive pressure directed into the top of the collection bag, and 